\begin{tabular}{ll|l}
\hline Bentham OPEN & The Open Dentistry Journal \\
\hline CrossMark & Content list available at: www.benthamopen.com/TODENTJ/ & $\substack{\text { The } \\
\text { Open Dentistry } \\
\text { lournal }}$ \\
\hline
\end{tabular}

RESEARCH ARTICLE

\title{
Cone Beam CT-Based Preoperative Volumetric Estimation of Bone Graft Required for Lateral Window Sinus Augmentation, Compared with Intraoperative Findings: A Pilot Study
}

\author{
Nagla'a A. Abdel-Wahed ${ }^{1}$ and Maha Ahmed Bahammam, \\ ${ }^{\prime}$ Department of Oral Diagnostic Sciences, Faculty of Dentistry, King Abdulaziz University, Jeddah, Saudi Arabia \\ ${ }^{2}$ Department of Periodontology, Faculty of Dentistry, King Abdulaziz University, Jeddah, Saudi Arabia
}

Received: May 14, 2018

Revised: September 20, 2018

Accepted: October 4, 2018

\section{Abstract:}

\section{Introduction:}

The presence of an atrophic maxilla creates a serious challenge in cases of implant placement, while maxillary sinus pneumatization further complicates the surgery. This pilot study was performed to investigate the validity of two techniques used to estimate the volumes of bone graft material required in cases that included lateral window sinus augmentation.

\section{Materials and Methods:}

Cone beam computed tomography was used for preoperative volumetric analysis of the maxillary sinus. The analysis was performed using the manual measurement of sinus dimensions, as well as automated measurements via the segmentation technique. The estimated volumes of required bone graft material were compared with actual intraoperative findings in cases requiring lateral window sinus augmentation. For this pilot study, only 5 patients were selected to be included.

\section{Results:}

To achieve $80 \%$ power and confidence interval of $95 \%$, the sample size should be 35 patients. The correlation coefficient between the segmented volume and $\mathrm{mm}^{3}$ used was -0.5332 , whereas the coefficient between the manual volume and $\mathrm{mm}^{3}$ used was -0.6784 . Consequently, both results indicate that the two methods have a moderate negative correlation with the $\mathrm{mm}^{3}$ used.

\section{Conclusion:}

Performing a similar study with an increased number of patients, according to the calculated sample size, increases the possibility of revealing higher correlation between the methods used to analyze the partial volume of the sinus cavity. The estimated sinus volume of the area of augmentation, obtained by using either manual or segmentation techniques, could be considered as a maximum estimate for the required amount of graft material. Furthermore, the segmentation technique may be valuable in preoperative planning of sinus augmentation, as it reveals the topographic shape and morphology of the sinus.

Keywords: Volumetric estimation, Bone graft, Sinus augmentation, Dental implants, Cone beam CT, Pilot study.

\section{INTRODUCTION}

The presence of an atrophic maxilla creates a serious challenge in cases of implant placement, whereas maxillary sinus pneumatization further complicates the surgery. Patients who exhibit both conditions require bone grafting to the maxillary sinus floor to increase the height of the maxillary alveolar bone [1 - 7]. Lateral window sinus lift or Schneiderian membrane elevation is a common surgical procedure, first published by Boyne and James in 1980, that

\footnotetext{
* Address Correspondence to this author at the Department of Periodontology, Faculty of Dentistry, King Abdulaziz University, P. O. Box 80209, Jeddah 21589, Kingdom of Saudi Arabia; Tel: +966505303227; E-mail: mbahammam@kau.edu.sa
} 
is used to create a window on the lateral wall of the sinus, as well as a space between the Schneiderian membrane and the sinus walls for the placement of grafting materials. Lateral window sinus lift is an effective procedure to gain bone height to facilitate future implant placement in an atrophic pneumatized posterior maxilla [1].

Preoperative planning includes radiographic assessment of maxillary sinus dimensions. Digital panoramic radiographs have been used [8], but they exhibit no ability to investigate depth. Conventional dental or panoramic radiographs are not suitable for volumetric analysis, as their two-dimensional nature only provides an approximation of sinus graft vertical dimensions. Thus, 3D imaging is required to allow investigation of the presence of bony septa, as well as Schneiderian membrane thickness and residual alveolar bone height $[9,10]$, thereby allowing the proper design of the lateral wall sinus augmentation.

Several previous studies have used Computed Tomography (CT) as a method for sinus anatomy evaluation and volume calculation [11 - 14]. Cone Beam CT (CBCT) has also been used with comparable accuracy [9, 15 - 18].

Generally, the need for decreased postoperative complications at the donor site (during autogenous graft surgeries) necessitates careful preoperative planning of the graft volume to be harvested. The increased cost of allografts leads to further urgency in preoperative planning.

This pilot study was performed to investigate the validity of two techniques used to estimate volumes of bone graft material, required in cases that included lateral window sinus augmentation, through CBCT imaging. The null hypothesis is that there is no statistical significance between the estimated volumes and actual intraoperative findings.

\section{MATERIALS AND METHODS}

This pilot study included patients who presented to the Department of Periodontology at King Abdulaziz University for the placement of dental implants in the maxillary posterior area. Patients were interviewed and examined to determine their eligibility for the study. Inclusion criteria were as follows: consent for the described procedure as approved by the University's Institutional Ethical Committee on Human Research, the requirement for lateral wall sinus augmentation prior to dental implant placement, and age $\geq 18$ years. Exclusion criteria were as follows: Ongoing pregnancy, diagnosis with metabolic disorder, immunocompromised status, hemophilia, bleeding disorders, drug or alcohol abuse, treatment with steroids, history of radiation therapy in the head and neck, psychiatric disorders, and/or inability to understand the procedure described in the questionnaire. The statistical tool determined the sample size, which was 35 patients at $80 \%$ power and confidence interval of $95 \%$. For this pilot study, only 5 patients were selected to be included.

3D imaging was performed before lateral wall sinus augmentation. CBCT images were acquired using a Next Generation i-CAT scanner (Imaging Sciences International, Inc., Hatfield, USA). A scout (preview) was obtained and adjustments were made to ensure that the patient was correctly aligned in the scanner before acquisition, using the adjustment light beam. The machine was supplied with an Amorphous Silicon Flat Panel Sensor with Cesium Iodide (CsI) scintillator (0.5-mm focal spot size, 14-Bit grayscale resolution) and operated at the following protocol for all the scans of the study: $120 \mathrm{kVp}, 37.07 \mathrm{mAs}, 8.9 \mathrm{~s}, 0.4 \mathrm{~mm}$ Voxel size, and $13 \times 16 \mathrm{~cm}^{2} \mathrm{FOV}$.

Following acquisition, data were exported and transferred in DICOM format, then downloaded via a Compact Disk (CD) to a personal computer for volume measurement, where Mimics software (version 15.1; Materialize, Belgium) was utilized.

Data were imported into Mimics software; at the coronal view, the edentulous site was viewed, and a 12-mm vertical linear measurement was made from the crest of the ridge upwards (at the area of minimum dimension). Next, the axial reference line was moved to the site at the end of the previous measurement; this level was assigned as the level up to which segmentation of the maxillary sinus space should reach. A certain threshold was assigned to segment the sinus space; then cropping and region-growing tools were used to confine the segmented mask to the maxillary sinus space. Final fine-tuning and clean-up steps were performed at the axial cut sites to ensure the geometry of the segmented mask. After calculating the volume of the segmented mask, the software presented the amount of graft material required to augment the sinus, thereby reaching 12-mm bone height [15].

Additionally, manual measurements were performed of the sinus dimensions and volume calculation. These were dependent on the anatomical fact that the maxillary sinus is pyramidal in shape, with an almost square base that is oriented medially [16]. At the coronal view, the edentulous site was viewed, and a 12-mm vertical linear measurement was taken from the crest of the ridge upwards (at the area of minimum dimension). Next, the axial reference line was 
moved to the site at the end of the previous measurement; this level was assigned as the level up to which linear measurements will be performed. To obtain the width, length, and height of the sinus, the coronal, axial, and sagittal cuts were sequentially reviewed to acquire maximum sinus mediolateral, anteroposterior, and craniocaudal dimensions.

Finally, radiographic data was compared to intraoperative findings and statistically evaluated by correlation analysis.

This study was approved by the Research Ethics Committee of the Faculty of Dentistry, King Abdulaziz University (No. 009-16).

\section{RESULTS}

The statistical tool determined the sample size, which was 35 patients at $80 \%$ power and confidence interval of $95 \%$.

Results obtained from this pilot study done for 5 patients are as follows: Table 1 represents the correlation coefficient between each of the two methods and $\mathrm{mm}^{3}$ used. The correlation coefficient between the mimics volume and $\mathrm{mm}^{3}$ used was -0.5332 , whereas the coefficient between the manual volume and $\mathrm{mm}^{3}$ used was -0.6784 . The resulting linear regression models were as follows:

Estimated $\mathrm{mm}^{3}$ used $=-0.1865 \times$ Mimics volume +2094.5

Estimated $\mathrm{mm}^{3}$ used $=-0.4162 \times$ manual volume +2149

Table 1. Maxillary sinus volumetric analysis.

\begin{tabular}{|c|c|c|}
\hline $\begin{array}{c}\text { Actual Volume of Material Used } \\
\left(\mathbf{m m}^{\mathbf{3}}\right)\end{array}$ & $\begin{array}{c}\text { Estimated Volume from Mimics } \\
\left(\mathbf{m m}^{\mathbf{3}}\right)\end{array}$ & $\begin{array}{c}\text { Estimated Volume from Manual Calculation } \\
\left(\mathbf{m m}^{\mathbf{3}}\right)\end{array}$ \\
\hline 1500 & 2179 & 1030.36 \\
\hline 2000 & 1997 & 396.03 \\
\hline 2000 & 1319 & 1098.24 \\
\hline 1500 & 1693 & 1241.86 \\
\hline 1500 & 3389 & 1628.03 \\
\hline $\boldsymbol{r}$ & $\mathbf{- 0 . 5 3 3 2}$ & $\mathbf{- 0 . 6 7 8 4}$ \\
\hline
\end{tabular}

The two models above were used to estimate the $\mathrm{mm}^{3}$ used, based on the given Mimics volume and manual volume values. The residual error was measured and normalized to obtain the coefficient of determination (i.e., $\mathrm{R}^{2}$ ) of the model. The calculated $\mathrm{R}^{2}$ values for the two models above were 0.2843 and 0.4603 , respectively.

Figs. (1 and 2) depict snapshots of manual and Mimics volumetric calculations for the patients.

\section{DISCUSSION}

In this pilot study, CBCT was used for preoperative volumetric analysis of the maxillary sinus. The estimated volumes of required bone graft material were compared with actual intraoperative findings. Although the determined sample size was 35, considering the nature of this study (pilot), number of patients was limited to five.

To assess the ability of the measured volume parameters to accurately predict the actual $\mathrm{mm}^{3}$ used, the correlation coefficient was evaluated between each of the two methods and the $\mathrm{mm}^{3}$ used. Briefly, the correlation generally measures the existence and strength of a linear model between two variables; the correlation coefficient used produces results between +1 (strong positive linear dependence) and -1 (strong negative linear dependence), with 0 indicating no relationship between the two variables. Thus, the closer the magnitude of the correlation coefficient to 1 , the more plausible a linear model is to describe the relationship. The results indicate that the two methods have a moderate negative correlation with the $\mathrm{mm}^{3}$ used.

The next step in estimating the validity of the linear model was to perform a linear regression to generate an estimate of the $\mathrm{mm}^{3}$ used, from the value of either the Mimics volume or the manual volume. Furthermore, to check the goodness-of-fit of the resulting linear models, both models were used to estimate the $\mathrm{mm}^{3}$ used, based on the given Mimics volume and manual volume values. The residual error was measured and normalized to obtain the coefficient of determination (i.e., $\mathrm{R}^{2}$ ) of the model. This metric has a value between 0 and 1 , where 1 designates a perfect linear model. Hence, the larger the value of $\mathrm{R}^{2}$, the better the model to accurately predict the data. 
The results of this pilot study were more towards rejecting the null hypothesis. Performing a similar study according to the calculated sample size, may reveal a higher correlation between the methods used to analyze the partial volume of the sinus cavity and actual intraoperative findings. However, in this study, the model based on manual volume exhibited a much better goodness-of-fit.

In a previous study [16], manual calculation of the whole sinus used the laws of geometry to give an estimated volume, which significantly correlated with the estimation via segmentation technique. Previous studies also incorporated manual or automated segmentation to assess sinus or grafted bone volume [13, 14, 19, 20]. Uchida et al. $[13,14]$ investigated the volume of grafted bone required for sinus floor lifting and determined a range of $4.74-7.96 \mathrm{~cm}^{3}$ graft volume, depending on the height of required sinus floor lift, which ranged from 15-20 mm. It has been also reported that the calculated augmentation volume for an augmentation height of $12 \mathrm{~mm}$ was $1.7 \pm 0.9 \mathrm{~cm}^{3}[21]$. These ranges reasonably consistent with the results of this study, as the level of lift was set at $12 \mathrm{~mm}$.

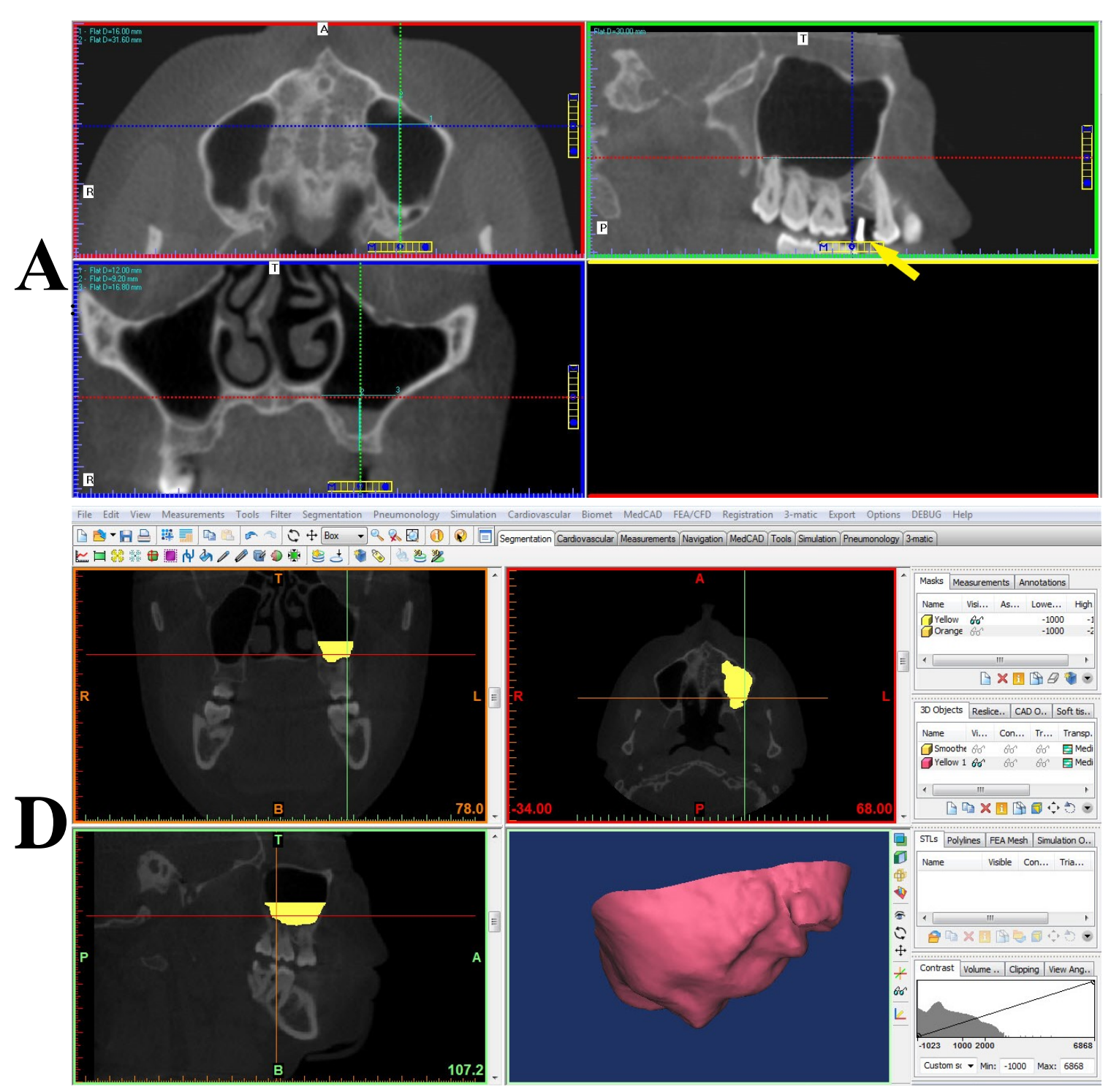

Fig. (1). A: Snapshot showing the linear measurements used to calculate the sinus volume for a patient (yellow arrow points at the radiopaque marker inserted in the imaging stent); B: Snapshot showing calculation of the sinus volume for the same patient, performed with the Mimics program. 

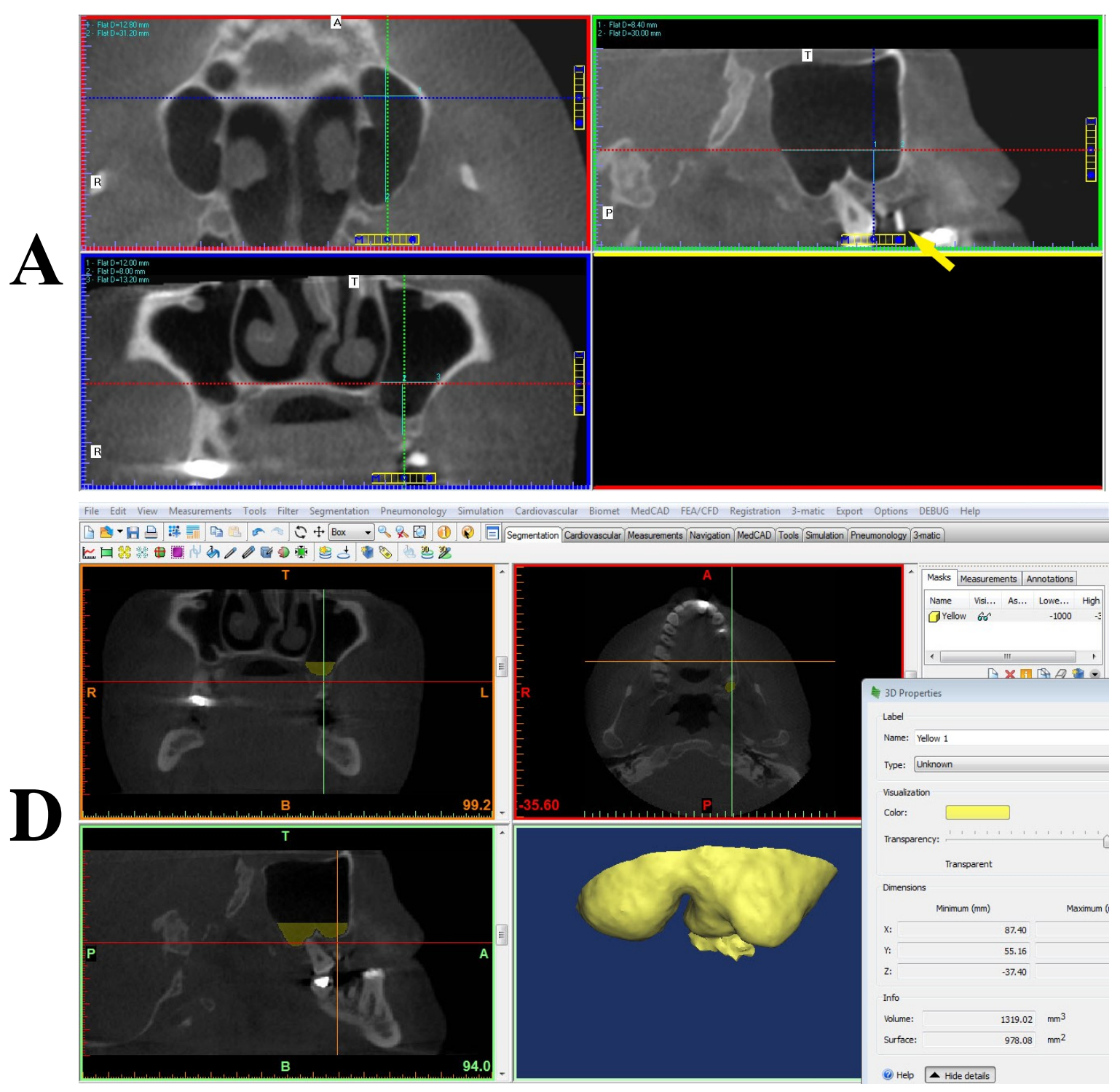

Fig. (2). A: Snapshot showing the linear measurements used to calculate the sinus volume for a patient (yellow arrow points at the radiopaque marker inserted in the imaging stent); B: Snapshot showing calculation of the sinus volume for the same patient, performed with the Mimics program.

The segmentation technique by Mimics provides additional advantages, as it reveals the topographic shape and morphology of the sinus, thereby informing the surgeon of the anatomical limitations expected. However, the inaccuracy of the model's goodness-of-fit cannot be disregarded. Thus, the estimated volumes should be used only as a guide. The greater value of the Mimics method (or any other segmentation technique) lies in its accurate morphological representation of sinus anatomy. The resulting 3D shapes provide an ideal preoperative guide for the clinician.

\section{CONCLUSION}

Performing a similar study with an increased number of patients, according to the calculated sample size, increases the possibility of revealing higher correlation between the methods used to analyze partial volume of the sinus cavity. The estimated sinus volume of the area of augmentation, obtained by using either manual or segmentation techniques, could be considered as a maximum estimate for the required amount of graft material. Furthermore, the segmentation technique may be valuable in preoperative planning of sinus augmentation, as it reveals the topographic shape and 
morphology of the sinus.

\section{LIST OF ABBREVIATIONS}

$\begin{array}{lll}\text { CT } & = & \text { Computed Tomography } \\ \text { CBCT } & = & \text { Cone Beam Computed Tomography } \\ \text { CsI } & = & \text { Cesium Iodide } \\ \text { CD } & = & \text { Compact Disk }\end{array}$

\section{ETHICS APPROVAL AND CONSENT TO PARTICIPATE}

This study was approved by the Research Ethics Committee of the Faculty of Dentistry, King Abdulaziz University (No. 009-16).

\section{HUMAN AND ANIMAL RIGHTS}

No animals were used in this research. All research procedures followed were in accordance with the ethical standards of the committee responsible for human experimentation (institutional and national), and with the Helsinki Declaration of 1975 , as revised in 2008.

\section{CONSENT FOR PUBLICATION}

Informed consent was obtained from all patients prior to being enrolled in the study.

\section{CONFLICT OF INTEREST}

The authors declare no conflict of interest, financial or otherwise.

\section{ACKNOWLEDGEMENT}

The authors would like to thank Prof. Yasser Moustafa Kadah, Professor of Biomedical Engineering, Faculty of Engineering, King Abdulaziz University, for his valuable assistance in the statistical analysis performed in this work. They would also thank Dr. Ahmad Ali Hassan, Assistant Lecturer of Oral and Maxillofacial Radiology, Faculty of Dentistry, Fayoum University, for his valuable assistance in the Mimics program manipulation.

\section{REFERENCES}

[1] Boyne PJ, James RA. Grafting of the maxillary sinus floor with autogenous marrow and bone. J Oral Surg 1980; 38(8): 613-6. [PMID: 6993637]

[2] Hochwald DA, Davis WH. Bone grafting in the maxillary sinus floor. In: Worthington P, Brånemark PI, Eds. Advanced Osseointegration Surgery: Application in the Maxillary Region. Chicago: Quintessence Publishing 1992; pp. 175-81.

[3] Isaksson S. Evaluation of three bone grafting techniques for severely resorbed maxillae in conjunction with immediate endosseous implants. Int J Oral Maxillofac Implants 1994; 9: 679-88.

[4] Keller EE, Eckert SE, Tolman DE. Maxillary antral and nasal one-stage inlay composite bone graft: Preliminary report on 30 recipient sites. J Oral Maxillofac Surg 1994; 52(5): 438-47. [http://dx.doi.org/10.1016/0278-2391(94)90335-2] [PMID: 8169704]

[5] Kent JN, Block MS. Simultaneous maxillary sinus floor bone grafting and placement of hydroxylapatite-coated implants. J Oral Maxillofac Surg 1989; 47(3): 238-42.

[http://dx.doi.org/10.1016/0278-2391(89)90225-5] [PMID: 2646403]

[6] Li KK, Stephens WL, Gliklich R. Reconstruction of the severely atrophic edentulous maxilla using Le Fort I osteotomy with simultaneous bone graft and implant placement. J Oral Maxillofac Surg 1996; 54(5): 542-6. [http://dx.doi.org/10.1016/S0278-2391(96)90626-6] [PMID: 8632236]

[7] Sailer HF. A new method of inserting endosseous implants in totally atrophic maxillae. J Craniomaxillofac Surg 1989; 17(7): 299-305. [http://dx.doi.org/10.1016/S1010-5182(89)80057-5] [PMID: 2808708]

[8] Machtei EE, Rozitky D, Zigdon-Giladi H, Horwitz J. Dimensional changes following lateral wall sinus augmentation without concomitant implant placement using a composite bone graft. Int J Oral Maxillofac Implants 2016; 31(1): 87-91. [http://dx.doi.org/10.11607/jomi.4084] [PMID: 26800165]

[9] Gurler G, Delilbasi C. Relationship between preoperative cone beam computed tomography and intraoperative findings in sinus augmentation. Int J Oral Maxillofac Implants 2015; 30(6): 1244-8. [http://dx.doi.org/10.11607/jomi.3797] [PMID: 26574849] 
[10] Tadinada A, Jalali E, Al-Salman W, Jambhekar S, Katechia B, Almas K. Prevalence of bony septa, antral pathology, and dimensions of the maxillary sinus from a sinus augmentation perspective: A retrospective cone-beam computed tomography study. Imaging Sci Dent 2016; 46(2): 109-15.

[http://dx.doi.org/10.5624/isd.2016.46.2.109] [PMID: 27358818]

[11] Ariji Y, Ariji E, Yoshiura K, Kanda S. Computed tomographic indices for maxillary sinus size in comparison with the sinus volume. Dentomaxillofac Radiol 1996; 25(1): 19-24. [http://dx.doi.org/10.1259/dmfr.25.1.9084281] [PMID: 9084281]

[12] Ariji Y, Kuroki T, Moriguchi S, Ariji E, Kanda S. Age changes in the volume of the human maxillary sinus: A study using computed tomography. Dentomaxillofac Radiol 1994; 23(3): 163-8. [http://dx.doi.org/10.1259/dmfr.23.3.7835518] [PMID: 7835518]

[13] Uchida Y, Goto M, Katsuki T, Akiyoshi T. A cadaveric study of maxillary sinus size as an aid in bone grafting of the maxillary sinus floor. J Oral Maxillofac Surg 1998; 56(10): 1158-63.

[http://dx.doi.org/10.1016/S0278-2391(98)90761-3] [PMID: 9766541]

[14] Uchida Y, Goto M, Katsuki T, Soejima Y. Measurement of maxillary sinus volume using computerized tomographic images. Int J Oral Maxillofac Implants 1998; 13(6): 811-8. [PMID: 9857592]

[15] Hamdy RM, Abdel-Wahed N. Cone-beam computed tomographic volumetric analysis of the maxillary antra for sinus augmentation. Egypt Dent J 2012; 58(4): 3157-65.

[16] Hamdy RM, Abdel-Wahed N. Three-dimensional linear and volumetric analysis of maxillary sinus pneumatization. J Adv Res 2014; 5(3): 387-95. [http://dx.doi.org/10.1016/j.jare.2013.06.006] [PMID: 25685506]

[17] Loubele M, Van Assche N, Carpentier K, et al. Comparative localized linear accuracy of small-field cone-beam CT and multislice CT for alveolar bone measurements. Oral Surg Oral Med Oral Pathol Oral Radiol Endod 2008; 105(4): 512-8 [http://dx.doi.org/10.1016/j.tripleo.2007.05.004] [PMID: 17900939]

[18] Neugebauer J, Ritter L, Mischkowski RA, et al. Evaluation of maxillary sinus anatomy by cone-beam CT prior to sinus floor elevation. Int J Oral Maxillofac Implants 2010; 25(2): 258-65. [PMID: 20369083]

[19] Gultekin BA, Borahan O, Sirali A, Karabuda ZC, Mijiritsky E. Three-dimensional assessment of volumetric changes in sinuses augmented with two different bone substitutes. Biomed Res Int 2016; 2016 pp. 7.

[20] Okada T, Kanai T, Tachikawa N, Munakata M, Kasugai S. Long-term radiographic assessment of maxillary sinus floor augmentation using beta-tricalcium phosphate: Analysis by cone-beam computed tomography. Int J Implant Dent 2016; $2(1): 8$. [http://dx.doi.org/10.1186/s40729-016-0042-6] [PMID: 27747700]

[21] Krennmair G, Krainhöfner M, Maier H, Weinländer M, Piehslinger E. Computerized tomography-assisted calculation of sinus augmentation volume. Int J Oral Maxillofac Implants 2006; 21(6): 907-13.

[PMID: 17190300]

(C) 2018 Abdel-Wahed and Bahammam

This is an open access article distributed under the terms of the Creative Commons Attribution 4.0 International Public License (CC-BY 4.0), a copy of which is available at: https://creativecommons.org/licenses/by/4.0/legalcode. This license permits unrestricted use, distribution, and reproduction in any medium, provided the original author and source are credited. 